\title{
Segurança do trabalho voltada ao préstimo do seguimento da NR-10 em empresas da construção civil: uma revisão de literatura
}

\author{
Work safety aimed at the use of NR-10 follow-up in construction \\ companies: a literature review
}

\author{
1 Emanuel Rodrigo Reis da Silva rodrigoreis405@gmail.com http://orcid.org/0000-0002-1626-0611 \\ 2 Humberto Denys de Almeida Silva http://orcid.org/0000-0002-3144-7070 \\ 2 Hitalo de Jesus Bezerra da Silva http://orcid.org/0000-0001-6008-3600 \\ 2 Samuel Jônatas de Castro Lopes http://orcid.org/0000-0002-9520-414X
}

1 Universidade Federal do Maranhão.

2 Universidade Federal do Piauí.

\section{Resumo}

A segurança do trabalho deve ser entendida como um conjunto de ações desempenhadas com a finalidade de mitigar os incidentes e as doenças ocupacionais. Nesse sentido, destaca-se a importância em discutir o papel da proteção ocupacional do trabalhador que atua no campo da eletricidade em firmas do setor da construção civil, haja vista que esses profissionais são expostos cotidianamente a uma série de riscos que podem desencadear consequências extremamente graves à saúde. Este artigo tem como objetivo discutir o emprego da Segurança do Trabalho em instalações e serviços em eletricidade dos canteiros de obras à luz da NR-10. Para sua concepção, realizou-se uma pesquisa bibliográfica considerando as contribuições de diversos autores, procurando enfatizar a importância do bom convívio entre empregadores, empregados e a normatização regulamentadora das atividades que envolvam o uso da eletricidade, bem como a necessidade e o préstimo de uma política de segurança eficaz e eficiente nas organizações empregatícias. Concluiu-se que uma boa gestão de riscos nas organizações traz benefícios tanto à vida e bem-estar do corpo de colaboradores, quanto à saúde financeira da firma.

\section{Palavras-chave:}

Segurança do trabalho. Construção civil. Eletricidade. Saúde ocupacional.

\begin{abstract}
Occupational safety must be understood as a set of actions performed with the purpose of mitigating incidents and occupational diseases. In this sense, it is important to discuss the role of occupational protection for workers who work in the field of electricity in companies in the construction sector, since that these professionals are daily exposed to a series of risks that can trigger extremely serious consequences to health. This article discusses the use of Work Safety in electrical installations and services at construction sites in light of NR-10. A bibliographical research was carried out considering the contributions of several authors, seeking to emphasize the importance of good interaction between employers, employees and the regulatory standardization of activities involving the use of electricity, as well as the need and the usefulness of an effective and efficient safety policy in employment organizations. It was concluded that good risk management in organizations brings benefits both to the life and well-being of the body of employees, as well as to the financial health of the firm.
\end{abstract}

\section{Keywords:}

Work safety. Construction. Electricity. Occupational health.

\section{Como você deve citar?}

SILVA, Emanuel Rodrigo Reis da et al. Segurança do trabalho voltada ao préstimo do seguimento da nr-10 em empresas da construção civil: uma revisão de literatura. Cadernos UniFOA, Volta Redonda (RJ), v. 16, n. 47, p. 37 - 42, dez, 2021. 
O segmento da construção civil tem um elevado índice de empregabilidade, sendo apontado, conforme a Associação Nacional de Medicina do Trabalho (2019), como o responsável por 1,8 milhão postos de trabalhos gerados no país no ano de 2017, porém, esse mesmo setor também é apontado como um dos que mais causa incapacidades permanentes e mortes em atividades laborais no Brasil (FILGUEIRAS et al., 2015), haja vista que há um vasto ajuntamento de riscos aos quais são expostos os trabalhadores dessa área, por ser composta por uma larga diversidade de serviços, materiais e categorias de obras.

Nessa esteira, a Associação Nacional de Medicina do Trabalho (2019) denotou que a taxa de mortalidade no segmento da construção civil, no Brasil, foi de 11,76 casos para cada 100 mil vínculos empregatícios no ano de 2019, sendo apontadas como problemáticas mais contundes e corriqueiras à saúde do colaborador desse setor: as alergias, quedas, choques elétricos, cortes e fraturas (MEDICAR, 2021).

O cumprimento dos preceitos de Segurança do Trabalho dentro das organizações se faz importante para minimizar ou eliminar os acidentes no ambiente de trabalho. De acordo com Bristot (2019), a segurança do trabalho deve ser entendida como um conjunto de ações desempenhadas com a finalidade de mitigar os incidentes e as doenças ocupacionais, o que, para Chiavenato (2020), é possibilitado por meio da adoção de um conglomerado de medidas técnicas, educativas, médicas e psicológicas empenhadas, com vista à redução e eliminação de condições inseguras à operacionalização das atividades e dos meios de laboração nas organizações.

Atualizada pela Portaria n. ${ }^{\circ}$ 598, do Ministério do Trabalho, no ano de 2004 (BRASIL, 2004), a Norma Regulamentado n. ${ }^{\circ} 10$, visa garantir um arcabouço consultivo capaz de orientar as condições e princípios mínimos a serem seguidos para a implantação de medidas de controle e prevenção em atividades cujos meios e os fins pertençam ao setor laboral da eletricidade (BRASIL, 2008).

Nesse contexto, o objetivo da presente pesquisa foi discutir o emprego da Segurança do Trabalho em instalações e serviços em eletricidade dos canteiros de obras, por meio de um estudo bibliográfico amparado pela literatura disponível sobre a temática, à luz da norma regulamentadora NR-10.

\section{METODOLOGIA}

O presente estudo foi baseado em uma pesquisa bibliográfica, de abordagem exploratório-descritiva, a qual se deu a partir da seleção e leitura de artigos científicos e outras publicações importantes relacionados à temática.

A pesquisa bibliográfica constitui-se pela averiguação de materiais já elaborados acerca de uma temática. À vista disso, a pesquisa ora desenvolvida dividiu-se em duas etapas: a primeira consistiu no levantamento bibliográfico, o que neste trabalho tomou-se, como fonte de dados consultivos, o normativo regulamentador do Ministério do Trabalho que versa sobre segurança dos profissionais nas ações laborais que compreendem as diligências com eletricidade, bem como as fontes literárias e jurídicas disponíveis sobre o tema, dando total enfoque na proteção dos profissionais do setor elétrico nos canteiros de obras, com o objetivo de se conhecer e analisar as contribuições científicas do passado existente sobre o assunto. Foram utilizados no estudo: artigos, leis e normas regulamentadoras (LAKATOS e MARCONI, 2017).

Foram considerados como principais autores para o levantamento de dados deste trabalho: Associação Nacional de Medicina do Trabalho (2019), Barros et al. (2010), Brasil (2008), Bristot (2019), Câmara Brasileira 
da Indústria da Construção (2020), Filgueiras et al. (2015), Macedo et al. (2017), Martins et al. (2010), Medicar (2021), Mello (2007), Oliveira e Veiga (2012), Oliveira (2011), Santos (2013), Silva (2016).

\section{RISCOS E POSTURAS RELACIONADOS A ACIDENTES DE TRABALHO NO SETOR DE CONSTRUÇÃO CIVIL}

A construção civil é um segmento econômico e industrial com fortes características de heterogeneidade, sendo composta por uma vasta gama de atividades que abrigam os mais diversos graus de complexidade, produtos e processos tecnológicos (MELLO, 2007). Em nações industrializadas, o setor da construção civil ocupa os mais elevados índices de contribuição para o produto interno bruto dos países (YOON et al., 2013) e ocorre porque o processo produtivo no setor de infraestrutura contribui significativamente para a geração de empregos e renda das famílias pertencentes às classes média e baixa (PEINADO, 2019).

Nesse contexto, segundo a Câmara Brasileira da Indústria da Construção (2020), o macro setor da infraestrutura compôs cerca de $3,9 \%$ do produto interno bruto do Brasil, no ano de 2018 , e empregou cerca de seis milhões e oitocentos e sessenta mil pessoas, no terceiro semestre do ano de 2019 , sendo $63 \%$ destes informais e $37 \%$ formais.

Assim, por se tratar de um segmento industrial com alto teor de empregabilidade também é denotado como o setor laboral que mais gera perigos, sequelas e acidentes graves, quando relacionamos as atividades ocupacionais com a saúde do trabalhador no Brasil (MARTINS et al., 2010), o que para Lee et al. (2020) tem recorrência potencializada e agravada por fatores como: as atitudes dos funcionários no ambiente de trabalho, o tamanho das instituições empregatícias, a coordenação de projetos nas firmas, a pressão organizacional interna e externa de ascensão econômica e desempenho produtivo, a falta de treinamento e gerenciamento de riscos nos canteiros de obras, bem como o desleixo da cultura empresarial frente às ações de segurança do trabalho.

A pressão imposta aos coordenadores de projetos e obras, bem como aos técnicos de segurança para o atendimento de uma demanda produtiva cada vez mais volumosa e complexa nas organizações industriais, faz com que os procedimentos de segurança e controle de riscos sejam, por vezes, violados pelos supervisores e pelos operários nos canteiros de obras, o que torna a relação trabalho/acidente muito mais próximas do cotidiano dos funcionários desse setor (YE et al., 2018).

Conforme disposto no artigo dezenove da Lei Federal n. ${ }^{\circ}$ 8.213, de 1991,

acidente de trabalho é o que ocorre pelo exercício do trabalho a serviço da empresa ou pelo exercício do trabalho dos segurados referidos no inciso VII do art. 11 desta lei, provocando lesão corporal ou perturbação funcional que cause a morte ou a perda ou redução, permanente ou temporária, da capacidade para o trabalho (BRASIL, 1991).

Nessa perspectiva, Peixoto (2010) caracteriza, como acidentes do trabalho, os incidentes acontecidos no meio ambiente laboral e causados por: conflitos, agressões, desentendimentos, sabotagens, imprudências, imperícias, negligências, inexperiências, desabamentos, incêndios, inundações e outros, capazes de acarretarem prejuízos e consequências para os indivíduos acometidos, para as empresas contratantes e para o Estado.

Denota-se que ocorra um acidente laboral no Brasil a cada 48 segundos, sendo registrados, no período compreendido entre janeiro de 2012 e novembro de 2018, cerca de quatro milhões e quatrocentos mil incidentes de trabalho, sendo que noventa e sete mil ocorridos no setor da construção civil (MINISTÉRIO PÚBLICO DO TRABALHO, 2018; SILVA, 2016). 


\section{PROTEÇÃO DOS PROFISSIONAIS DE ELETRICIDADE NO SETOR DA CONSTRUÇÃO CIVIL}

A Segurança do Trabalho pode ser dita como a ciência que, por meio de métodos e técnicas, visa possibilitar e desenvolver ações preventivas eficientes para a redução e eliminação das ocorrências de acidentes no meio ambiente de trabalho (BRISTOT, 2019). Desse modo, criou-se, em 1978, no Brasil, um conjunto de Normas Regulamentadoras com a finalidade de se obter um arcabouço técnico consultivo capaz de balizar as atividades pontuais e preventivas dessa ciência, sendo a Norma Regulamentadora n. ${ }^{\circ} 10$ a responsável por nortear os procedimentos de segurança em trabalhos realizados com eletricidade em território nacional (BARROS et al., 2010), É importante ressaltar que esse conjunto normativo foi inteiramente revisado e atualizado no ano de 2004 (BRASIL, 2004).

Dessa forma, a atividade profissional do eletricista pode ser ranqueada como uma das mais bem requisitadas no mercado de trabalho, bem como uma daquelas que possuem os mais altos índices de periculosidades para a saúde e bem-estar dos profissionais (OLIVEIRA, 2011), podendo ser destacado como riscos frequentes nas atividades e organizações do ramo elétrico, segundo Silva (2016), o contato direto do operário ou veículos com equipamentos energizados, bem como equipamentos instalados de forma errada ou danificados e em contato com condutores de eletricidade.

Nesse sentido, a Norma Regulamentadora n. ${ }^{\circ} 10$ aponta que a perfeita forma de resguardo do profissional contra incidentes elétricos se dá pela proteção adequada do próprio corpo, ou seja, pelo uso inegociável dos Equipamentos de Proteção Individual, tais como aqueles que protegem o tronco, a face, os membros superiores, inferiores e a cabeça, atendendo aos requisitos de condutibilidade, inflamabilidade e influências de cargas eletromagnéticas (SANTOS, 2013).

Ao tratar dos procedimentos de segurança e imputabilidade da responsabilidade no asseguramento e cumprimento efetivo, eficaz e eficiente das orientações técnicas e normativas relacionadas ao meio ambiente de trabalho dos profissionais da área elétrica, a Norma Regulamentadora $n .{ }^{\circ} 10$ dispõe que cabe aos operários zelar por sua segurança própria e de terceiros, bem como também o cumprimento efetivo da normativa em vigor e a comunicação aos supervisores das possíveis situações de riscos que permeiam o ambiente laboral, no entanto, é de inteira responsabilidade do empregador oferecer os meios mínimos necessários para sanar demandas apresentadas pelos empregados que versem sobre a segurança das pessoas, dos equipamentos, das instalações e da qualidade de trabalho oferecida (BRASIL, 2004).

Dessa maneira, denota-se que, em âmbito legal, jurídico e normativo, a Norma Regulamentadora n. ${ }^{\circ} 10$ detém de capacidade e força para agregar e formalizar instruções que acumulem valores indispensáveis para a qualidade, presteza, eficácia dos serviços e bem-estar do trabalhador.

Nesse sentido, uma organização não deve focar-se apenas no produto ou serviço oferecido ao público-alvo, mas também na qualidade e garantia de saúde, segurança e integridade metal e corporal de seus funcionários, tornando-se visível que a segurança ocupacional nas organizações empresariais deve ser alocada como um valor fundamental e indispensável ao planejamento estratégico e cultural da empresa (OLIVEIRA E VEIGA, 2012; CHIAVENATO, 2020).

A absorção da cultura de prevenção de riscos em organizações prestadoras de serviços relacionados ao campo elétrico reduz bruscamente não só as chances de que um trabalhador seja submetido a uma descarga elétrica, a um campo eletromagnético ou a um arco elétrico, mas também os custos diretos e indiretos de acidentes, ou seja, os gastos desencadeados pelo não seguimento das normas de segurança (SILVA, 2016; BARROS et al., 2010). 
As empresas que valorizam em sua cultura organizacional o préstimo do respeito às normas de segurança dos colaboradores gozam de vantagens econômicas e competitivas de extrema valia, haja vista que detêm de uma redução dos custos com seguros para acidentes, custos salariais das vítimas, custos com reparos a danos materiais, custos com tempo de investigação de causas, custos com perda de produção, custos com socorros, custos com desagravo da imagem pública da organização e outros (OLIVEIRA, 2014; MACEDO et al., 2017).

\section{CONSIDERAÇÕES FINAIS}

Diante do exposto, conclui-se que as normativas regulamentadoras e jurídicas destinadas à proteção da saúde do trabalhador no ambiente laboral abrangem uma vasta quantidade de prevenções a fatores que podem resultar em sinistros e, desse modo, se torna possível assegurar que o cumprimento dos preceitos estabelecidos à segurança do trabalhador nas organizações gera uma maior lucratividade às empresas, haja vista que reforçam o valor à vida, que, no que lhe concerne, reflete na saúde financeira, cultural e social da firma.

\section{REFERÊNCIAS}

ASSOCIAÇÃO NACIONAL DE MEDICINA DO TRABALHO. Construção civil está entre os setores com maior risco de acidentes de trabalho. 2019. Disponível em: https://www.anamt.org.br/portal/2019/04/30/ construcao-civil-esta-entre-os-setores-com-maior-risco-de-acidentes-de-trabalho. Acesso em: 01 jun. 2021.

BARROS, B. F de. et al. NR-10 Norma Regulamentadora de Segurança em Instalações e Serviços de Eletricidade: Guia Prático de Análise e Aplicação. 1. ed. São Paulo: Érica, 2010.

BRASIL. Lei n. ${ }^{\circ}$ 8.213, de 24 de julho de 1991. Dispõe sobre os Planos de Benefícios da Previdência Social e dá outras providências. 1991. Disponível em: http://www.planalto.gov.br/ccivil_03/leis//8213cons. htm. Acesso em: 24 jun. 2021.

BRASIL. Ministério do Trabalho e Emprego. NR-10 - Instalações e Serviços em Eletricidade: Segurança e Medicina do Trabalho. São Paulo: Editora Saraiva, 2008.

BRASIL. Portaria n. ${ }^{\circ}$ 598, de 07 de dezembro de 2004. Alterar a Norma Regulamentadora n. ${ }^{\circ} 10$ que trata de Instalações e Serviços em Eletricidade, aprovada pela Portaria $n^{\circ} 3.214$, de 1978, que passa a vigorar na forma do disposto no Anexo a esta Portaria. 2004. Disponível em: http://www.trabalhoseguro. com. Acesso em: 02 mar. 2021.

BRISTOT, Vilson Menegon. Introdução à Engenharia de Segurança do Trabalho. Criciúma: UNESC, 2019. 260 p.

CÂMARA BRASILEIRA DA INDÚSTRIA DA CONSTRUÇÃO. Banco de Dados da Câmara Brasileira da Indústria da Construção, de fevereiro de 2020. 2020. Disponível em: http://cbic.org.br. Acesso em: 05 jun. 2021.

CHIAVENATO, I. Recursos Humanos. 11. ed. São Paulo: Atlas, 2020.

FILGUEIRAS, V. A. et al. Saúde e segurança do trabalho na construção civil brasileira. J. Andrade, 2015.

LAKATOS, E.; MARCONI, M. de A. Técnicas de pesquisa: planejamento e execução de pesquisas, amostragens e técnicas de pesquisas, elaboração, análise e interpretação de dados. 8. ed. São Paulo: Atlas, 2017. 
LEE, Y. C.; SHARIATFAR, M.; RASHIDI, A.; LEE, H. W. Evidence-driven sound detection for prenotification and identification of construction safety hazards and accidents. 2020. Disponível em: https://www. researchgate.net. Acesso em: 22 jun. 2021.

MACEDO, G. C. G. et al. Levantamento dos Custos Indiretos de Acidentes do Trabalho em uma Empresa do Setor Elétrico. XXXVII Encontro Nacional de Engenharia de Produção. Joinville, Santa Catarina. 2017.

MARTINS, M. S. et al. Segurança do trabalho: Estudos de casos nas áreas agrícola, ambiental, construção civil, elétrica, saúde. Porto Alegre: SGE, 2010.

MEDICAR. Os tipos mais comuns de acidentes na Construção Civil. 2021. Disponível em: www.medicar. com.br. Acesso em: 02 mar. 2021.

MELLO, L.C. B. B. Modernização das pequenas e médias empresas de Construção Civil: impactos dos programas de melhoria da gestão da qualidade. 2007. Tese (Doutorado em Engenharia Civil) - Programa de Pós-Graduação em Engenharia de Civil, Universidade Federal Fluminense, Niterói, 2007.

MINISTÉRIO PÚBLICO DO TRABALHO. Construção Civil registra 97 mil acidentes no país, $4^{\circ}$ setor com mais ocorrências. 2018. Disponível em: https://protecao.com.br. Acesso em: 10 jun. 2021.

OLIVEIRA, D. de P. R. Estratégia Empresarial e Vantagem Comparativa. 9. ed. São Paulo: Atlas, 2014.

OLIVEIRA, M; VEIGA, C. H. A. Segurança e Saúde no Trabalho em Cooperativa de Distribuição de Energia Elétrica: Percepção dos Colaboradores. Revista Brasileira de Ergonomia. Universidade Federal de Santa Maria. Santa Maria, 2012.

OLIVEIRA, R. L. S. Metodologia para Avaliar as Condições de Saúde e Segurança do Eletricista de Manutenção da lluminação Pública. 2011. Monografia (Especialização em Engenharia de Segurança do Trabalho) - Escola de Engenharia, Universidade Federal do Rio Grande do Sul, Porto Alegre, 2011.

PEINADO, Hugo Sefrian. Segurança e Saúde do Trabalho na Indústria da Construção Civil. 1. ed. São Carlos: SCIENZA, 2019. 436 p.

PEIXOTO, N. H. Curso técnico em automação industrial: segurança do trabalho. 3. ed. Santa Maria: Colégio Técnico Industrial de Santa Maria, 2010.

SANTOS, F. F. dos. Principais consequências da não aplicação da NR-10: Avaliação das instalações elétricas de baixa tensão de uma unidade militar de aquartelamento. Curitiba, 2013.

SILVA, Mauricio Dias Paixão. Prevenção de acidentes nas instalações elétricas. Orientador: Jorge Luiz do Nascimento. 2016. 123 p. (Monografia) - Escola Politécnica, Universidade Federal do Rio de Janeiro, [S. I.], 2016.

YE, G. et al. Improved HFACS on Human Factors of Construction Accidents: A China Perspective. 2018. Disponível em: https://www.researchgate.net. Acesso em: 22 jun. 2021.

YOON, S. J. et al. Effect of occupational health and safety management system on work-related accident rate and differences of occupational health and safety management system awareness between managers in South Korea's construction industry. Safety and health at work. 2013. Disponível em: https://www. ncbi.nlm.nih.gov. Acesso em: 22 mar. 2021. 